Supporting information of the paper

\title{
Proteins Take up Water Before Unfolding
}

\author{
Carien C.M. Groot and Huib J. Bakker*
}

FOM institute AMOLF, Science Park 104, 1098 XG Amsterdam, The Netherlands

\section{Corresponding Author}

*bakker@amolf.nl

\section{Contents}

1. Experimental methods

2. Supporting figures 


\section{Experimental methods}

The reorientation dynamics of water are studied using polarization-resolved femtosecond infrared spectroscopy ${ }^{1}$. The infrared pulses are generated by frequency conversion of the output of a Ti:sapphire regenerative amplifier producing $900 \mu \mathrm{J}, 100$ femtosecond pulses with a central wavelength of $800 \mathrm{~nm}$ at a repetition rate of $1 \mathrm{kHz}$. Part of the light is used to pump a $\beta$-bariumborate (BBO)-based optical parametric amplifier that produces $1.3 \mu \mathrm{m}$ signal and 2 $\mu \mathrm{m}$ idler pulses. The idler pulses are frequency-doubled in another BBO crystal and subsequently mixed with the remaining $800 \mathrm{~nm}$ light in a lithiumniobate crystal to produce 10 $\mu \mathrm{J}$ pulses centered at $4 \mu \mathrm{m}\left(2500 \mathrm{~cm}^{-1}\right)$, with a bandwidth of $100 \mathrm{~cm}^{-1}$ and a pulse duration of 200 fs. These pulses are split into pump, probe and reference beams by a wedged $\mathrm{CaF}_{2}$ window and focused into the sample by a parabolic mirror. The sample consists of a protein solution in between two $\mathrm{CaF}_{2}$ windows that are held apart by a $50 \mu \mathrm{m}$ spacer layer. After passing through the sample, the probe and reference beams are recollimated using a second parabolic mirror, dispersed by a grating, and detected by a $3 \times 32$ mercury-cadmium-telluride (MCT) array.

Bovine $\alpha$-lactalbumin (purity $>90 \%$, Davisco foods), bovine $\beta$-lactoglobulin (purity $>90 \%$, mixture of type A and B, Davisco foods), bovine serum albumin (purity $>96 \%$, Sigma) and hen egg-white lysozyme (70000 U/mg, Fluka) are used without further purification. Each protein is dissolved in isotopically diluted water, consisting of ultrapure milli-Q grade $\mathrm{H}_{2} \mathrm{O}$ and $4 \% \mathrm{D}_{2} \mathrm{O}(99.9 \% \mathrm{D}$, Cambridge Isotope Laboratories). The protein concentrations are determined using their molar extinction coefficient $(\varepsilon)$ at $280 \mathrm{~nm}: \varepsilon=2.01 \mathrm{~g} \mathrm{~g}^{-1} \mathrm{~cm}^{-1}, 0.958 \mathrm{mg}^{-}$ ${ }^{1} \mathrm{~cm}^{-1}, 0.6606 \mathrm{mg}^{-1} \mathrm{~cm}^{-1}$ and $2.67 \mathrm{mg}^{-1} \mathrm{~cm}^{-1}$ for $\alpha$-lactalbumin, $\beta$-lactoglobulin, serum albumin and lysozyme respectively. In the experiments with urea, the proteins are dissolved with urea (purity $>98 \%$, Sigma-Aldrich) in isotopically diluted water. The solution $\mathrm{pH}$ is left unadjusted and ranges between 7.0 and 7.2 for $\alpha$-lactalbumin and $\beta$-lactoglobulin, between 6.6 and 6.8 for serum albumin and between 4.2 and 4.8 for lysozyme, depending on the urea concentration. Control experiments with small added amounts of $\mathrm{NaOH}$ or $\mathrm{HCl}$ showed that there is no dependence of the water dynamics on $\mathrm{pH}$ within this range. All measurements are conducted at $24^{\circ} \mathrm{C}$.

To calculate the number of slowly reorienting water molecules from the measured anisotropy decay, the anisotropy at each protein concentration is fitted to an exponential decay and an offset: $R(t)=R_{0} \exp \left(-t / \tau_{r}\right)+R_{\text {slow }}$. Here $R_{\text {slow }}$ is the fraction of slowly reorienting water molecules $(>10 \mathrm{ps})$. This fraction increases linearly with the protein concentration in $\mathrm{mol} / \mathrm{kg}$. Hence, the number of slowly reorienting water molecules per protein molecule is given by the slope of $R_{\text {slow }}$ against the protein concentration, $R_{\text {slow }} / c$, multiplied by the number of moles of water in a kilogram (which is 55.257 for $4 \% \mathrm{D}_{2} \mathrm{O}$ in $\mathrm{H}_{2} \mathrm{O}$ ):

$N_{\text {slow }}=\frac{R_{\text {slow }}}{c} \cdot 55.257$

References

(1) Rezus, Y. L. A.; Bakker, H. J. On the Orientational Relaxation of HDO in Liquid Water. J. Chem. Phys. 2005, 123, 114502. 


\section{Supporting figures}
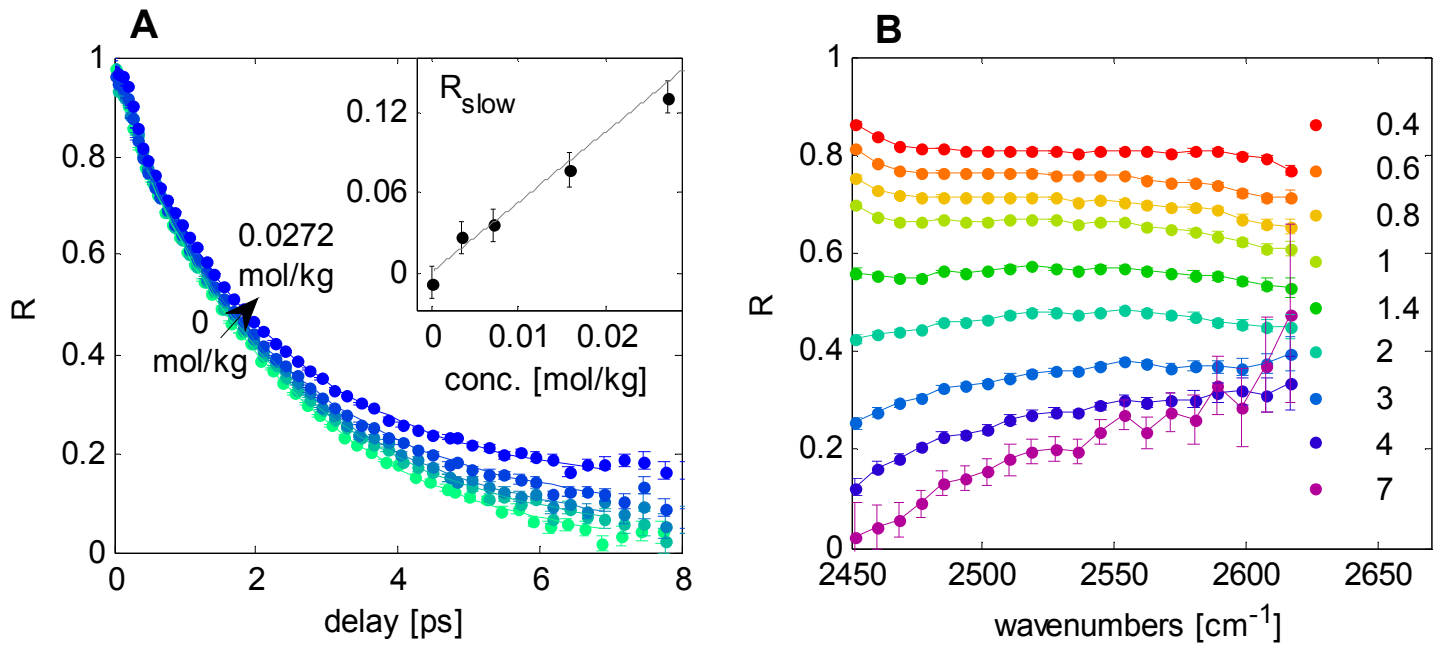

Figure S1. Water reorientational dynamics in aqueous lysozyme solutions. (A) Anisotropy decay of the OD stretch vibration for solutions of lysozyme in isotopically diluted water with concentrations up to $0.0272 \mathrm{~mol} / \mathrm{kg}$, averaged over the frequency range $2450-2600 \mathrm{~cm}^{-1}$. The solid lines are fits to a mono-exponential with an offset $\mathrm{R}_{\text {slow. }}$. The inset shows $\mathrm{R}_{\text {slow }}$ as a function of lysozyme concentration. (B) Anisotropy decay for $0.0272 \mathrm{~mol} / \mathrm{kg}$ lysozyme in isotopically diluted water as a function of frequency at different picosecond delay times.
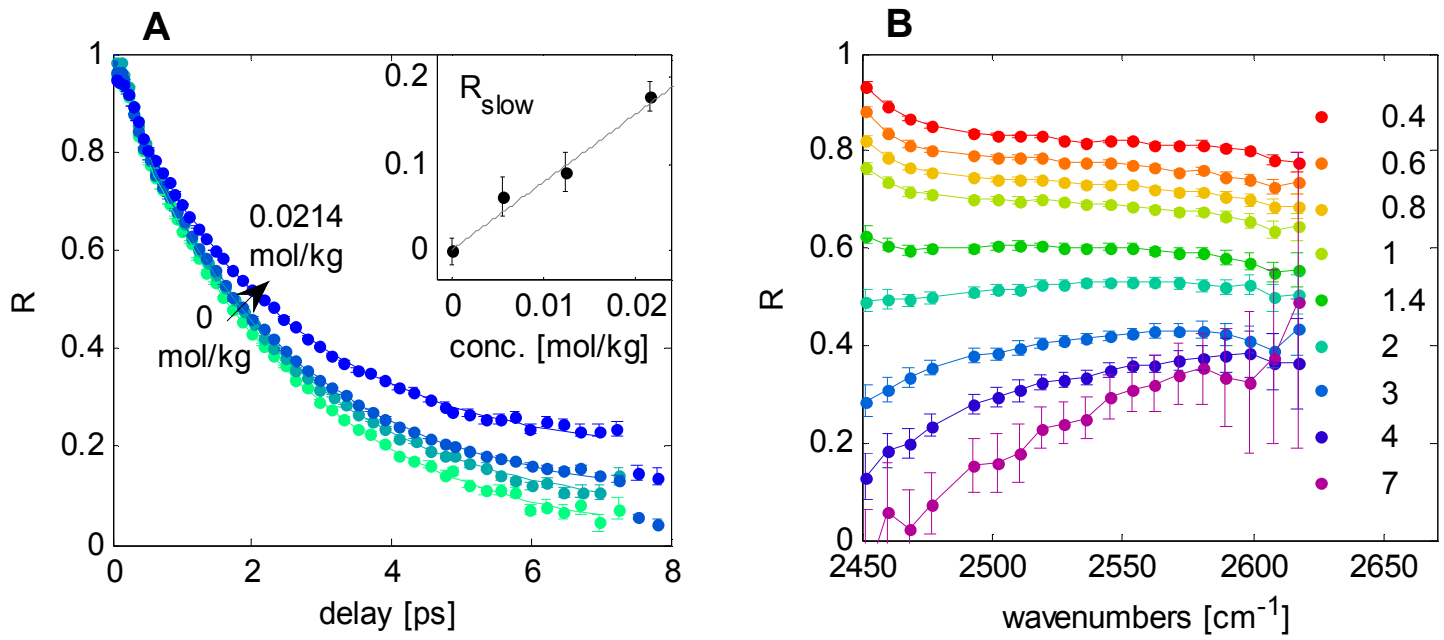

Figure S2. Water reorientational dynamics in aqueous $\beta$-lactoglobulin solutions. (A) Anisotropy decay of the OD stretch vibration for solutions of $\beta$-lactoglobulin in isotopically diluted water with concentrations up to $0.0214 \mathrm{~mol} / \mathrm{kg}$, averaged over the frequency range $2450-2600 \mathrm{~cm}^{-1}$. The solid lines are fits to a mono-exponential with an offset $\mathrm{R}_{\text {slow. }}$ The inset shows $\mathrm{R}_{\text {slow }}$ as a function of $\beta$-lactoglobulin concentration. (B) Anisotropy decay for 0.0214 $\mathrm{mol} / \mathrm{kg} \beta$-lactoglobulin in isotopically diluted water as a function of frequency at different picosecond delay times. 

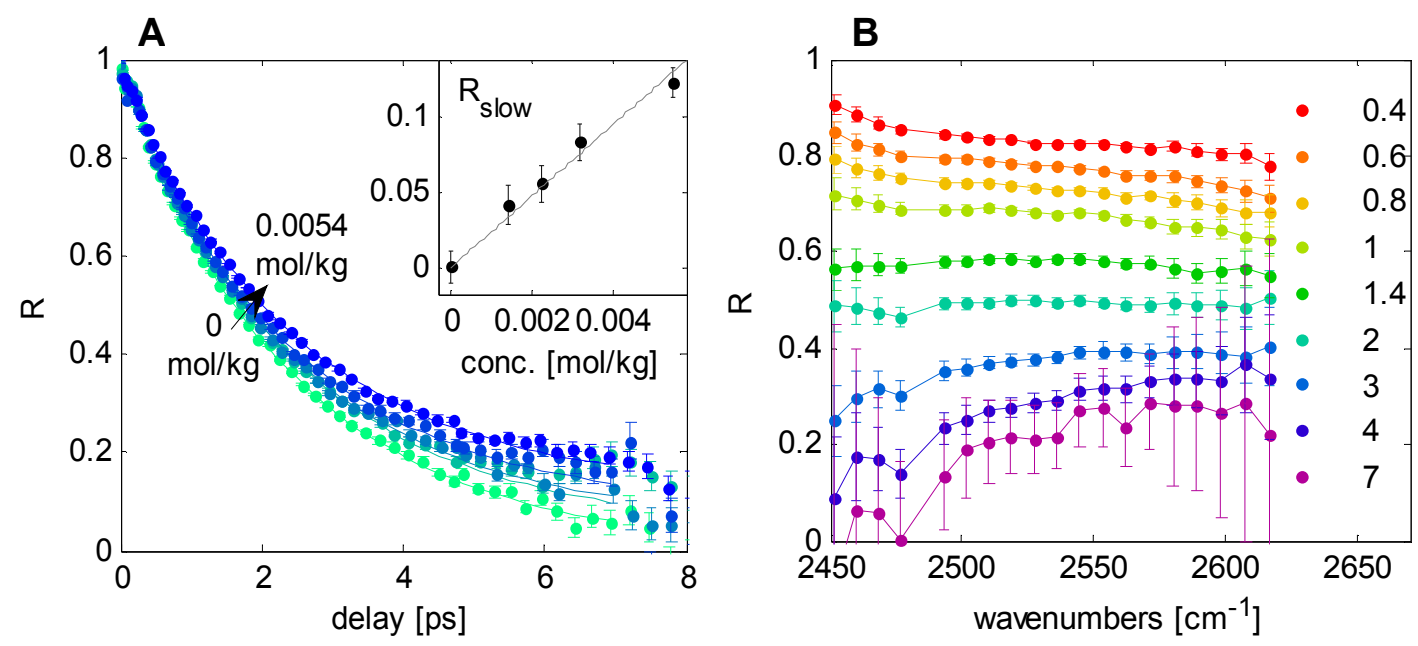

Figure S3. Water reorientational dynamics in aqueous serum albumin solutions. (A) Anisotropy decay of the OD stretch vibration for solutions of serum albumin in isotopically diluted water with concentrations up to $0.00544 \mathrm{~mol} / \mathrm{kg}$, averaged over the frequency range $2450-2600 \mathrm{~cm}^{-1}$. The solid lines are fits to a mono-exponential with an offset $\mathrm{R}_{\text {slow }}$. The inset shows $\mathrm{R}_{\text {slow }}$ as a function of serum albumin concentration. (B) Anisotropy decay for 0.00544 $\mathrm{mol} / \mathrm{kg}$ serum albumin in isotopically diluted water as a function of frequency at different picosecond delay times.
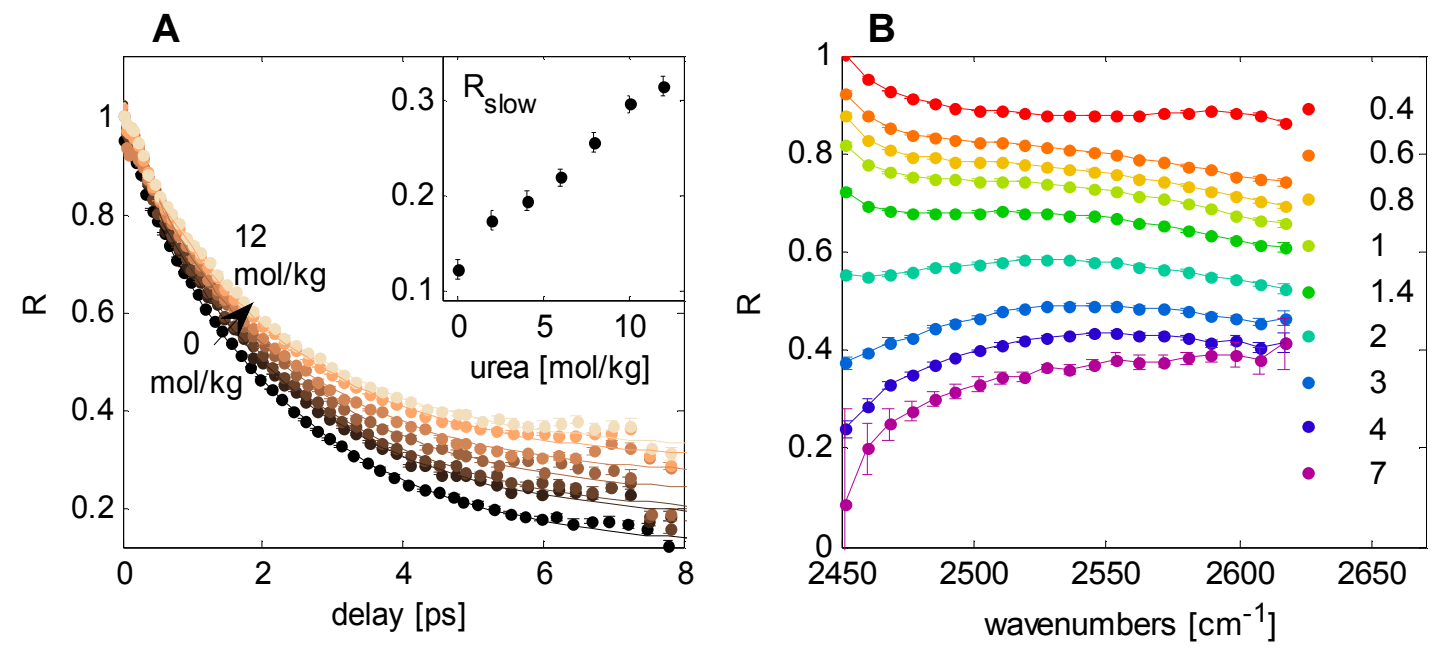

Figure S4. Effect of urea on the water reorientational dynamics in aqueous lysozyme solutions. (A) Anisotropy decay of the OD stretch vibration for $0.0248 \mathrm{~mol} / \mathrm{kg}$ lysozyme in isotopically diluted water with different concentrations of added urea, averaged over the frequency range $2450-2600 \mathrm{~cm}^{-1}$. The solid lines are fits to a mono-exponential with an offset $R_{\text {slow }}$ The inset shows $R_{\text {slow }}$ as a function of urea concentration. (B) Anisotropy decay for $0.0248 \mathrm{~mol} / \mathrm{kg}$ lysozyme in $10 \mathrm{~mol} / \mathrm{kg}$ urea solution as a function of frequency at different picosecond delay times. 

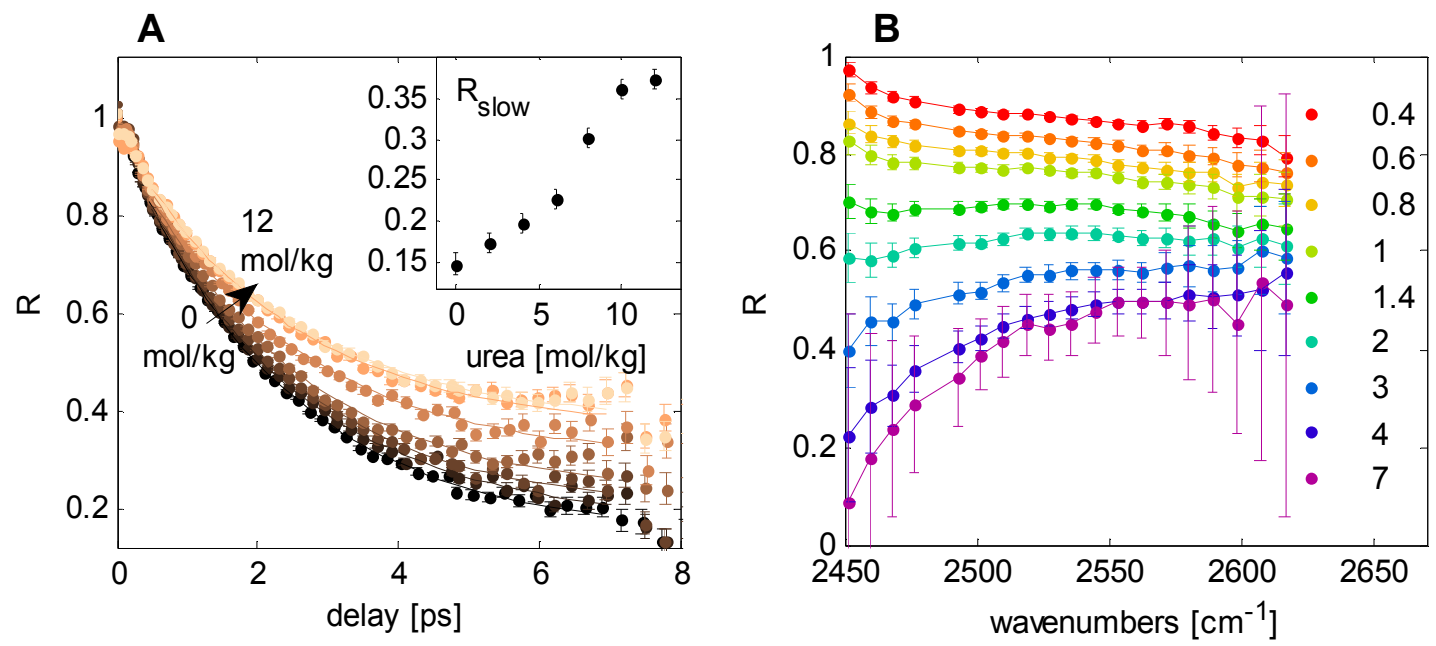

Figure S5. Effect of urea on the water reorientational dynamics in aqueous serum albumin solutions. (A) Anisotropy decay of the OD stretch vibration for $0.00544 \mathrm{~mol} / \mathrm{kg}$ serum albumin in isotopically diluted water with different concentrations of added urea, averaged over the frequency range $2450-2600 \mathrm{~cm}^{-1}$. The solid lines are fits to a mono-exponential with an offset $\mathrm{R}_{\text {slow. }}$. The inset shows $\mathrm{R}_{\text {slow }}$ as a function of urea concentration. (B) Anisotropy decay for $0.00544 \mathrm{~mol} / \mathrm{kg}$ serum albumin in $10 \mathrm{~mol} / \mathrm{kg}$ urea solution as a function of frequency at different picosecond delay times.

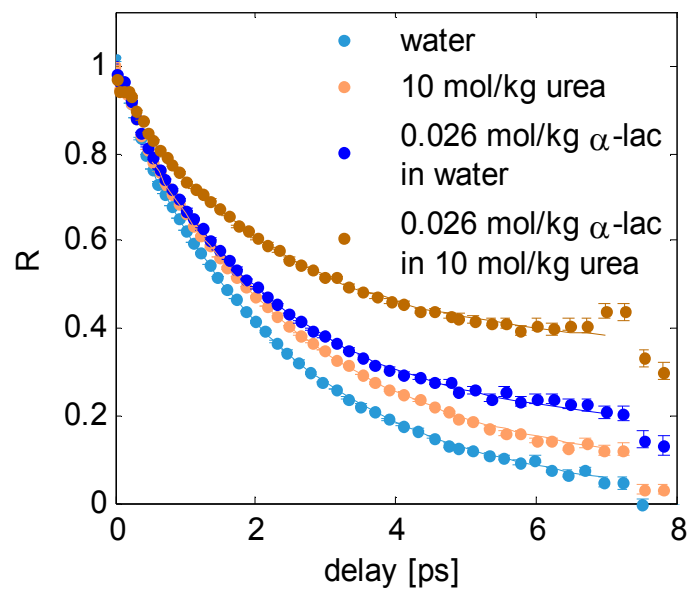

Figure S6. Effect of urea on the water reorientational dynamics. Anisotropy decay of the OD stretch vibration averaged over the frequency range $2450-2600 \mathrm{~cm}^{-1}$, for water, $10 \mathrm{~mol} / \mathrm{kg}$ urea, $0.0255 \mathrm{~mol} / \mathrm{kg} \alpha$-lactalbumin in water and $0.0255 \mathrm{~mol} / \mathrm{kg} \alpha$-lactalbumin in $10 \mathrm{~mol} / \mathrm{kg}$ urea (all isotopically diluted). The slow water fraction for $\alpha$-lactalbumin in $10 \mathrm{~mol} / \mathrm{kg}$ urea is much larger than the added slow water fractions for $10 \mathrm{~mol} / \mathrm{kg}$ urea and $\alpha$-lactalbumin in water. 